\title{
COVID-19 AND VIOLENT CRIME: A COMPARISON OF RECORDED OFFENCE RATES AND DYNAMIC FORECASTS (ARIMA) FOR MARCH 2020 In QueEnsland, Australia
}

A PREPRINT

\author{
Jason L. Payne* \\ Centre for Social Research and Methods \\ Australian National University
}

\author{
Anthony Morgan \\ Australian Institute of Criminology
}

May 2020

\begin{abstract}
At the time of writing, there was 2.9 million confirmed cases of COVID-19 and more than 200,000 deaths worldwide. Not since the Spanish Flu in 1918 has the world experienced such a widespread pandemic and this has motivated many countries across globe to take a series of unprecedented actions in an effort to curb the spread and impact of the SARS-CoV-2 virus. Among these government and regulatory interventions includes unprecedented domestic and international travel restrictions as well as a raft of stay-at-home and social distancing regulations. Each has left criminologists wondering what impact this will have on crime in both the short- and long-term. In this study, we examine officially recorded violent crime rates for the month of March, 2020, as reported for the state of Queensland, Australia. We use ARIMA modeling techniques to compute six-month-ahead forecasts of common assault, serious assault, sexual offence and domestic violence order breach rates and then compare these forecasts (and their 95\% confidence intervals) with the observed data for March 2020. We conclude that the observed rates of reported violent offending across Queensland were not-at least not so far-significantly different from what was expected given the history of each offence series.
\end{abstract}

\section{Introduction}

The World Health Organisation (WHO) declared the novel coronavirus disease 2019 (COVID-19) outbreak, caused by severe acute respiratory syndrome coronavirus-2 (SARS-CoV-2), to be a public health emergency of international concern on 30 January 2020 (World Health Organization, 2020)). Since this time, countries around the world have been affected in unprecedented ways. The number of infections has risen quickly, as has the number of deaths attributed to the virus. At the time of writing there was 2.9 million confirmed cases of COVID-19 and more than 200,000 deaths worldwide. An important focus has been on the capacity of the health system in each country to respond to the pandemic. The early experience of China, followed by countries such as Italy, Iran and more recently the United Kingdom and United States, where health systems have quickly become overwhelmed and struggled to cope with the demand from large numbers of infected patients, has motivated countries to take drastic action and implement a wide range of proactive and reactive measures to limit the spread of COVID-19.

Collectively referred to as 'containment measures', these strategies are designed to limit community transmission between individuals. There is, unsurprisingly, a great deal of variation in the ways in which different countries have approached the pandemic, and the types of containment measures they have employed. Despite these differences, each jurisdiction's response has involved some combination of travel restrictions and border controls, quarantine requirements, social isolation and distancing requirements, and the large-scale closure of various services, business and educational facilities. While the primary concern of government has been to minimise the health impacts of COVID-19, attention has also turned to the other effects of the pandemic. Significant societal and economic impacts have raised questions about potential increases in organised crime (Global Initiative Against Transnational Organized Crime, 2020), cybercrime (Europol, 2020) and violent crime (Eisner and

\footnotetext{
${ }^{*}$ Corresponding author: jason.payne@anu.edu.au
} 
Nivette, 2020), particularly domestic violence (Fitz-Gibbon and Meyer, 2020; van Gelder et al., 2020). Conversely, reductions in opportunistic, property crimes have been anticipated (Farrell and Tilley, 2020). The impact of COVID-19 on law enforcement (Lum et al., 2020), courts (Rossner and Tait, 2020; Sarat, 2020) and correctional systems (Kinner et al., 2020) have also been the subject of speculation and analysis. Here the focus has been primarily on the emerging health risks and the impact of containment measures on how these agencies and systems operate.

Particular attention has focused on the need for research into the impact of COVID-19 and associated containment measures on violent crime (Eisner and Nivette, 2020; Peterman et al., 2020). Changes in the routine activities of individuals, limited social interaction, the potential strain on relationships, fear and anxiety resulting from isolation, and the financial stress of job losses and reduced incomes, each have the potential to influence violent crime in different ways. Understanding these impacts is important to inform how to respond, particularly as the pandemic and containment measures are likely to persist for some time yet.

In this study, we use officially recorded police data from Queensland, Australia, to look for early signs that violent crime has changed in the context of the COVID-19 pandemic. In an international context, Australia is a unique site of analysis because the rapid introduction of strong social distancing regulations has coincided with the transition to winter-a time when seasonal crime rates are expected to fall. Without accounting for these seasonal effects, there is a risk that any observed short-term decline in crime may be overstated or wrongly attributed as a consequence of COVID-19. In this study, we examine officially recorded violent crime rates for the month of March 2020. We conduct this analysis in Queensland because it was the first state or territory in Australia to declare a public health emergency. It is also the first jurisdiction to provide open access to up to date data.

\subsection{What restrictions have been introduced in Australia?}

Compared with other countries, the infection rate in Australia has remained relatively low. The first Australian case was recorded in January, however, the number of new cases increased rapidly during March (Figure 1). There have been 6,720 confirmed cases recorded in Australia (as at 27 April) and, so far, 83 people have died as a result of the disease (Australian Government Department of Health, 2020). Most confirmed cases acquired their infection during overseas travel, or via contact with someone who had travelled overseas, and on-board cruise ships (Australian Government Department of Health, 2020).

[Figure 1 about here.]

Importantly, as a federated nation, responsibility for implementing containment measures is shared between the Federal and state and territory governments, while states and territories are able to choose how to enforce them. Although there has been a strong emphasis on a consistent national approach, there has also been variation in some of the measures employed in each jurisdiction. This has included strategies such as border controls and school closures.

Containment measures have been introduced incrementally. In terms of a national response, the entry of foreign nationals from mainland China was banned on 1 February, before incremental travel bans on Iran, South Korea and Italy in early March. This was followed by self-isolation requirements on all travellers arriving in Australia introduced on 16 March. Large, nonessential, organised public gatherings of more than 500 people were also restricted from this date, as were indoor gatherings of more than 100 people. At the same time, social distancing requirements were introduced, which required individuals to maintain a distance of 1.5 metres from one another. The Biosecurity (Human Biosecurity Emergency) (Human Coronavirus with Pandemic Potential) Declaration 2020 was announced on 18 March, followed by a further announcement that Australian borders were closed to all non-Australian citizens and non-residents effective 20 March. The following day, the requirement that there be 4 square metres per person in any enclosed space was introduced. On the 22 March the Prime Minister announced large-scale closures of on-premise licensed premises, restaurants and cafes (except for takeaway), entertainment venues and places of worship, which took effect the following day. Further restrictions were imposed on a range of other venues, including indoor and outdoor markets, on $26 \mathrm{March}$, while limits were placed on the number of people who are allowed to attend weddings and funerals. Public gatherings were limited to two people (non-family members) from 30 March, and Australians were advised that they were only allowed to leave home for essential shopping, medical needs, exercise, or for work or education.

Queensland became the first Australian state or territory to declare a public health emergency under the Public Health Act 2005 on 29 January. Since the non-essential business, activity and undertaking closure direction was first released on 23 March a series of revisions have been made in line with national requirements, imposing further limits on which venues and businesses may continue to operate. School closures came into effect on 30 March, remaining open to the children of essential service workers. Queensland borders were closed effective $26 \mathrm{March}$, with entry limited to Queensland residents, residents of border communities undertaking essential activities and other exempt persons. Non-residents were initially required to self-isolate for 14 days after crossing the border; however, as of early April, restrictions were tightened further and only Queensland residents could cross the border. These restrictions are enforceable by law. 


\subsection{Why is crime likely to be impacted by COVID-19?}

Broadly speaking, there are several mechanisms through which the COVID-19 containment measures are likely to influence violence. The first, and most obvious of these mechanisms, is the impact on the routine activities of individuals. Routine activities play an important role in understanding when and where crime is more likely to occur. According to Cohen and Felson (1979), crime occurs when there is a convergence of three critical elements-a motivated offender, a suitable target and the absence of a capable guardian. Crime is more common in places where these three things converge on a regular basis. Crime pattern theory combines aspects of the routine activity approach and other environmental criminological theories, and focuses on how offenders may come across opportunities for crime in the course of their everyday lives (Brantingham \& Brantingham, 1993). Brantingham and Brantingham (1995) describe crime as occurring when the activity spaces of offenders-which concentrate around the places they visit most frequently-intersect with the activity spaces of a target, precipitated by some triggering event. Obviously, major disruptions of these routine activities may have a significant impact on when, and where, we might expect crime to occur. Containment measures are likely to mean that much less time is spent interacting with other people in public settings, and much more time spent at home.

When asked, adult Australians have reported a high degree of compliance with recommended social distancing practices, including keeping distance between people, avoiding public spaces and avoiding large gatherings (Australian Bureau of Statistics, 2020). Google's (2020) mobility data highlights how much peoples' movement and time spent in public and private spaces has changed as a result of the containment measures. Location data reported by Google on community mobility has tracked how often and for how long people travel to different location types, compared with a baseline value (the median value for the same day of the week in January and early February). Figure 2 shows these changes over time, and demonstrates that there have been significant reductions in visits to public spaces, including parks (down 33\% as at mid-April), retail and recreation premises (down 37\%), workplaces (down 39\%) and transit stations (down 59\%). Conversely, the time spent in residential locations has increased by 20 percent.

[Figure 2 about here.]

Figure 3 describes the trend as at the end of March for Australia, overall, and for Queensland. This shows that the trends observed nationally were not as pronounced in Queensland. Nevertheless, the degree of change in mobility indicates that, in the second half of March, Queensland experienced significant changes in the mobility of its residents. It is possible, however, that these changes occur too late in the month to significantly influence monthly crime rates, analysed in the current study. That significant changes in mobility were observed in March, seemingly in advance of the introduction of major restrictions, indicates that people changed their behaviour in response to the perceived threat from the pandemic before measures were formally implemented. This is not unique to Australian residents; similar patterns have been observed elsewhere, where residents-informed by the risk of infection-engaged in social distancing before the measures announced by government were implemented (Midoes, 2020). However, most of the changes take effect in the second half of March, and are sustained through to mid-April.

[Figure 3 about here.]

Limiting the amount of time that people are permitted to spend outside of the home, and the number of people outside the home with whom people may have contact, reduces opportunities for interactions between potential victims and offenders. Spending significantly less time socialising in recreational areas, such as in entertainment precincts, may lead to less public forms of violence. A sizeable proportion of assaults—between 37 and 70 percent, depending on which state or territory-occur in public locations (Australian Bureau of Statistics, 2019). We know, for example, that a significant proportion of violent crime in Australia is attributable to the night time economy and peak on weekends during periods of high alcohol consumption, particularly in major urban centres (Miller et al., 2016). Excessive consumption of alcohol, common in these settings, is directly related to physical aggression, and is a contributing factor in physical and sexual violence (Graham et al., 1998). Rates of selfreported involvement in physical aggression in and around licensed premises in the previous three months among thousands of patrons surveyed in nine different cities ranged from seven to 17 percent (Miller et al., 2016). Entertainment precincts are also a known hotspot for sexual violence.

Conversely, the increase in time spent at home increases the risk of violence in residential locations. According to the latest ABS (2019) data, between 30 and 63 percent of assaults and between 40 and 73 percent of sexual assaults normally occur in residential settings (with most jurisdictions closer to the upper end of that range). This might be expected to increase during COVID-19. There is particular concern about the increased risk of family and domestic violence, which is already a significant problem in Australia (Fitz-Gibbon and Meyer, 2020; Usher et al., n.d.)Fitz-Gibbon \& Mayer, 2020; Nancarrow, 2020; Usher et al., 2020). The most obvious risk is from intimate partner violence, which accounts for more than half of all family violencerelated assaults (Australian Bureau of Statistics, 2019). Former partners may pose less of a threat (at least in terms of physical violence) in periods of social isolation; however, around four in five assaults by an intimate partner are committed by the victim's current partner (Australian Bureau of Statistics, 2019). Adolescent family violence is also an area of concern and, with 
the closure of schools and many recreational facilities, may increase due to increased contact between young people who use violence and their parents. As well as being at a greater risk of violence in the home due to increased contact with their abuser, victims of family and domestic violence face increasing social isolation, have limited opportunities to seek help from family and friends, may be unable or fearful of seeking help due to surveillance by their partner, or face challenges with seeking assistance from formal support services due to social distancing measures preventing face to face contact (Peterman et al., 2020; Usher et al., n.d.; van Gelder et al., 2020). This raises the potential risk of repeat violence.

Other factors exacerbate the risk of violence, particularly in the home. The pandemic and containment measures have exerted a significant financial strain on communities. An estimated 1.6 million Australians have lost their income as a direct consequence of the social distancing measures introduced in March (Janda, 2020). The proportion of Australians aged 18 years and over who had a job fell three percentage points between the first week of March and first week of April, while the proportion who currently worked paid hours fell by eight percentage points (Australian Bureau of Statistics, 2020). US research has shown the financial impacts of containment measures are most concentrated in low income households. The implication of this financial stress is not insubstantial; violence, including domestic violence, is concentrated in areas with higher socio-economic disadvantage (Hulme et al., 2019), while financial stress has been identified as a risk factor for repeat offending (Dowling and Morgan, 2016).

The restrictions on movement are likely to be compounded by the negative psychological impacts of quarantine measures. A recent rapid review by Brooks et al. (2020) concluded that there are wide ranging and long lasting psychological impacts, including a high prevalence of stress disorders, irritability, emotional disturbance, anger and depression, among other symptoms. Although this may not, in and of itself, lead to increased violence, people who experience these symptoms may be more likely to engage in substance misuse (Clay and Parker, 2020) which, together with poor mental health, is associated with an increased risk of violence (Elbogen and Johnson, 2009). Also, there is evidence of increased alcohol consumption in the home due to on-premise restrictions and increased home delivery (Foundation for Alcohol Research and Education, 2020). While debate persists regarding the causal role of substance use and domestic violence (Graham et al., 2010), these are situational stressors that can further exacerbate the risk of family and domestic violence.

\subsection{What trends have been observed around the world?}

Many countries have already released crime data to show the impact of COVID-19 on crime. In the United States, the Marshall Project analysed trends in overall crime numbers in four big cities-San Francisco, Detroit, Los Angeles and Chicago-in the week following stay at home orders (Weichselbaum and Li, 2020). Further analysis (of Chicago and two different cities, Austin and Chandler) revealed that domestic violence had also declined, but not by as much as overall crime. Elsewhere, there were media reports of significant decreases in violence in typically high crime countries, including South Africa (Marupeng, 2020) and several South America nations (Semple and Ahmed, 2020).

More rigorous analysis of local crime impacts in the United States have since been published. Mohler et al. ((2020)) analysed daily counts of calls for service in Indianapolis over a three-month period, divided into three time periods-(1) baseline period prior to 16 March, (2) the period between 16 and 23 March when schools and restaurants were closed, and (3) the period from 23 March when a shelter in place order was made. Using bootstrapping to compare mean daily call numbers for periods 2 and 3 with randomly selected, consecutive periods during the baseline period, they find a small overall effect on calls for service, especially given the level of disruption to routine activities. In terms of violent crime, robbery and assault/battery calls did not change in either period; however, domestic violence increased in period 2 and this increase was sustained in period 3 . They also found evidence of a small reduction in burglary calls, but an increase in vandalism.

Campedelli et al. (2020) analysed daily recorded crime counts over a three year period in Los Angeles using Bayesian structural time-series models, incorporating controls for weather (seasonality) and holiday periods. This approach allowed them to produce a synthetic counterfactual — what would have occurred had there been no containment measures-which they compared with observed crime counts during a period of increasingly stringent social distancing measures in March. They found no impact on homicide, assault with deadly weapons, intimate partner assault, but observed a decrease in robberies and battery (simple assault)-the latter only during the period with more stringent social distancing measures. Property crimes, including shoplifting and thefts, decreased, as did crime overall.

Most recently, Ashby (2020) analysed data for 16 large US cities. Similar to Campedelli (2020), Ashby forecasted the expected frequency of crime during the pandemic based on data from 2016 to early 2020, but used seasonal auto-regressive integrated moving average models to produce the synthetic counterfactual for the period after 20 January (the first confirmed case of COVID-19 in the US). There was no change in crime levels between the observed and predicted values before early March, when social distancing measures (like closing schools and then stay at home orders) were introduced. In terms of violent crime, there was no impact in any of the cities on serious assaults in public places or in residences. The latter was used as a proxy for domestic violence. There was some evidence of an impact on property crime, including burglary and theft from vehicles; however, Ashby observed significant variation between the cities and this raises questions about whether the observed declines are, in fact, the result of COVID-19 restrictions. 
Overall, there is only limited support for the suggestion that COVID-19 and associated containment measures has had an impact violent crime and, in the two more robust studies, there was no evidence of an impact on domestic violence (Ashby, 2020; Campedelli et al., 2020). Importantly, each of these studies has focused on the initial weeks following the introduction of containment measures, meaning that it might still be too early to have detected any meaningful impact on crime. The impact on simple assault in Los Angeles only emerged in the most recent iteration of the analysis, when social distancing measures had become more stringent. The limitations of using police recorded crime data to measure certain crime types when reporting rates might also be affected, particularly for domestic violence, were also acknowledged.

\subsection{How has COVID-19 impacted crime in Australia?}

Most of the evidence around the impact of crime impacts of COVID-19 in Australia is based on media reports, which draw on information supplied by police agencies. Limited detailed analyses have been conducted, although as the pandemic continues, it is likely that more and more data will become available and studies will be published. Further, it is recognised that many law enforcement agencies and other data custodians will be conducting their own in-house analyses of crime to help inform their respective government's response.

There is emerging evidence of the impact of restrictions on family violence and, to date, that evidence has produced something of a mixed picture. Some police jurisdictions have seen an increase in family violence incidents, others have not. WA Police has reported a five percent increase (Shepherd, 2020), but SA recently reported that their numbers have not changed (News, 2020). Victoria Police have reported 14 percent of incidents as being related to COVID-19 and the need for victims and perpetrators having to stay at home together (Davey, 2020). But there has been no increase in recorded assaults. Most recently, and in the only published analyses that we are aware of, the NSW Bureau of Crime Statistics and Research concluded there had been no increase in recorded domestic violence (Freeman, 2020). Freeman (2020) acknowledges that social isolation may have impacted the willingness or ability of victims to report to police; however, trends in serious forms of violence, less susceptible to changes in reporting rates, were also stable. There were limitations with the analysis; most notably, the study did not involve any time series analysis, rather, the frequency of recorded offences in March 2020 was compared with March 2019.

Data from other sources has provided a slightly different picture. 50 percent of domestic violence service providers in NSW reported an increase in demand following the onset of the pandemic in February (Women's Safety (NSW), 2020). But elsewhere, demand has not increased. In regional NSW, services have reported a decline in calls, raising concerns isolated victims can't reach out for help (Tate, 2020). Similarly, there has been reports of a decrease in calls to domestic violence helplines-falls by as much as $30 \%$ to 1800 RESPECT have been reported (Talwar, 2020) - but these numbers are climbing again (Pearson, 2020). Conversely, there has been an increase in calls to men's helplines from perpetrators reaching out for help to stop them from being violent (Tuohy, 2020). Finally, trauma surgeons in the Northern Territory have reported a 15 percent increase in surgeries related to domestic violence (Davey, 2020). However, none of these data sources have been subjected to rigorous analysis.

The problem with some of the published studies conducted to date-Australian and overseas-is that they have tended to rely on short time series. The benefit of shorter-term studies is that they have used daily offence counts and because of this they are able to detect immediate, short-term changes in crime. However, analysing short time periods does not account for longer term trends and seasonal variation that might occur, leading to masked or exaggerated effects. The same is true of studies that compare data for March 2020 with the same month in previous year (or years).

\section{Methodology}

\subsection{Data}

These data are drawn from the Queensland Government's Open Data Portal (Queensland Government, 2020). The ODP reports state-wide monthly offence rates per 100,000 of the Queensland population. The most recent addition to these data were for the month of March 2020-the same month in which the state of Queensland introduced significant social distancing regulations. For this study, we use the offence rates for four types of violent crime - common assault, serious assault, sexual offences and breaches of domestic violence orders.

\subsection{Analytical approach}

For each of the four violent offence categories, we operationalise an Auto Regressive Integrated Moving Average (ARIMA) model on the monthly offence rate between February 2014 and February 2020. ARIMA models are a specific type of time series forecasting technique which capitalise on several key time-series parameters-the series trend and seasonality, its lagged auto correlations and its lagged partial auto-correlations (correlations between residual errors). Put simply, past values of each time series are used to identify predictable patterns. These patterns are then used to specify a statistical model from which 
forecasts can be computed. Like all models, the relative accuracy of any forecast depends on the strength of the relationship between past and future values.

In each series, we exclude from the analysis the observed value for March 2020 since this is the month when social distancing restrictions were first introduced in Queensland. Each series also requires a unique ARIMA specification, depending on the presence (or absence) of seasonality and the unique nature of the series trend, auto-correlation and partial auto-correlation. Procedurally, we begin each model with a statistical assessment of the presence of a unit-root (non-stationarity). A unit-root is a stochastic trend which represents a systematic pattern that is unpredictable. Any time-series which evidence a unit-root must be first de-seasonalised or first-differenced before ARIMA modelling can be performed. To explore stationarity, the Augmented Dickey-Fuller (ADF) test is used. The null-hypothesis of the ADF test is that raw series is non-stationary (ie. includes a unitroot). Failure to reject the null-hypothesis at p0.05 indicates the presence of a unit-root and necessitates its removal.

Where there is some evidence of non-stationarity, the unit root is removed by seasonal and trend differencing. The raw series is used for subsequent ARMA modelling if the ADF test indicates stationarity. If not, the seasonality-differenced and firstdifferenced series is used, either separately or combined, depending on which produces the superior fit to the data. The base seasonality adjustment is $\operatorname{SARIMA}(0,1,0,12)$, where the purpose of seasonality differencing is to paramatise the additive seasonal patterns in the raw data. Second, and where needed, non-stationarity in the trend is removed using first-differencing. The base adjustment for non-stationarity in the trend is $\operatorname{ARMA}(0,1,0)$. Therefore, a series that requires both trend and seasonality differencing is known as $\operatorname{ARIMA}(0,1,0) \operatorname{SARIMA}(0,1,0,12)$.

Subsequent to any adjustments, each offence series is then explored using Auto-Correlation (AC) and Partial Auto-Correlation (PAC) plots. These plots help to determine the most likely specification of the seasonal and trend-level Moving Average (MA) and Auto Regressive (AR) parameters. From here the modelling is iterative and each specification seeks to identify the unique AR and MA specifications which best fit the observed data. As with all modelling, there is a trade-off between parsimony and best fit, so we use the Aikake Information Criteria (AIC) and the Baysian Information Criteria (BIC) to guide final model selection.

At the conclusion of the modelling procedure for each violent offence, we use the final ARIMA specification to forecast both point estimates and their mean square errors (MSE). The MSE is used to calculate $95 \%$ confidence intervals up to and including September 2020. We then compare the observed offence rate for March 2020 to the forecasted point estimate for the same month. We also consider its position within the confidence interval of the forecast and we only conclude that the offence rate has changed under COVID-19 conditions if the observed value (for March 2020) falls outside the upper or lower bounds of the $95 \%$ confidence interval.

\section{Results}

\subsection{Common assault}

Between February 2014 and February 2020, the rate of common assault in Queensland has fluctuated between 9.0 and 15.5 recorded offences per 100,000 of the population. The observed rate in March 2020 was 14.6 per 100,000, up on the previous month (13.5 per 100,000) and slightly lower than the same time in the previous year (15.1 per 100,000). Comparative tests (Table 1) confirm the need for both seasonality adjustment and trend-level first-differencing and inspection of the AC and PAC plots indicate significant auto-correlations at lags 1 and 12.

The specification that best fit these data was $\operatorname{ARIMA}(0,1,1 \& 12)$ SARIMA(0,1,0,12) (AIC=209.97). The modelled parameters are provided in Table 2 and a plot of the observed and model-derived estimates is provided in Figure 1. It shows that while the model captures the overall trend and some of the peaks and troughs, there is still some degree of variability (or 'noise') in the series that is not easily determined by patterns from within the data at earlier time points. This unpredictability necessarily makes forecasts less reliable and manifests as wide confidence intervals as seen in Figure 4.

As for March 2020 (see Figure 5), the observed rate of common assault (14.6 per 100,000) was almost equal with the forecasted rate $(14.7$ per 100,000$)$ and clearly falls well within the $95 \%$ confidence interval for that time period (between $12.9-16.5$ per 100,000). Therefore, we cannot conclude that the rate of common assault changed beyond expectations given the historical trends in that offence type.

[Figure 4 about here.]

[Figure 5 about here.] 
A PREPRINT - MAY 2020

Table 1: ARIMA Model Selection for COMMON ASSAULT (Feb 2014 - Feb 2020)

\begin{tabular}{|c|c|c|c|c|c|c|c|}
\hline Model & Description & Specification & Obs & 1l(model) & $\mathrm{df}$ & AIC & $\mathrm{BIC}$ \\
\hline 1 & Constant only & ARIMA $(0,0,0)$ SARIMA $(0,0,0,12)$ & 73 & -137.31 & 2 & 278.62 & 283.20 \\
\hline 2 & Seasonal differencing & ARIMA $(0,0,0)$ SARIMA $(0,1,0,12)$ & 73 & -125.93 & 1 & 253.87 & 256.16 \\
\hline 3 & Trend differencing & $\operatorname{ARIMA}(0,1,0) \operatorname{SARIMA}(0,0,0,12)$ & 73 & -120.77 & 1 & 243.54 & 245.83 \\
\hline 4 & Seasonal \& Trend differencing & $\operatorname{ARIMA}(0,1,0) \operatorname{SARIMA}(0,1,0,12)$ & 73 & -116.29 & 1 & 234.58 & 236.87 \\
\hline 5 & Model 4 with Seasonal MA1 & $\operatorname{ARIMA}(0,1,0) \operatorname{SARIMA}(0,1,1,12)$ & 73 & -105.11 & 1 & 212.21 & 214.50 \\
\hline 6 & Model 4 with Seasonal AR1 & $\operatorname{ARIMA}(0,1,0) \operatorname{SARIMA}(1,1,0,12)$ & 73 & -113.39 & 2 & 230.78 & 235.36 \\
\hline 7 & Model 4 with Seasonal AR1 \& MA1 & $\operatorname{ARIMA}(0,1,0) \operatorname{SARIMA}(1,1,1,12)$ & 73 & -104.49 & 2 & 212.97 & 217.55 \\
\hline 8 & Model 5 with Trend MA1 & $\operatorname{ARIMA}(0,1,1) \operatorname{SARIMA}(0,1,1,12)$ & 73 & -105.10 & 3 & 216.20 & 223.07 \\
\hline 9 & Model 5 with Trend AR1 & $\operatorname{ARIMA}(1,1,0) \operatorname{SARIMA}(0,1,1,12)$ & 73 & -107.99 & 3 & 221.98 & 228.85 \\
\hline 10 & Model 5 with Trend AR1 \& MA1 & ARIMA $(1,1,1) \operatorname{SARIMA}(0,1,1,12)$ & 73 & -104.60 & 4 & 217.21 & 226.37 \\
\hline 11 & Model 4 with Trend MA1 \& MA12 & $\operatorname{ARIMA}(0,1,1$ 12)SARIMA $(0,1,0,12)$ & 73 & -101.99 & 3 & 209.97 & 216.84 \\
\hline
\end{tabular}

Note: Final model indicated in bold. Source: Queensland Offence rates, Open Data Portal

Table 2: ARIMA Model parameters for COMMON ASSAULT (Feb 2014 - Feb 2020)

\begin{tabular}{lccc}
\hline \multicolumn{1}{c}{ coeff } & std. err. & $\mathrm{p}$ \\
\hline Trend & & & \\
MA1 & -0.45 & 0.13 & 0.00 \\
MA12 & -0.55 & 0.18 & 0.00 \\
/sigma & 0.93 & 0.09 & 0.00 \\
\hline
\end{tabular}

Model: ARIMA(0,1,1 12) SARIMA(0,1,0,12)

Source: Queensland Offence rates, Open Data Portal

\subsection{Serious assault}

Since February 2014 the rate of serious assault in Queensland has fluctuated between 12.2 and 21.3 offences per 100,000 of the population. In March 2020 the observed rate was 18.9 per 100,000. This was lower than previous month (19.5 per 100,000) and lower than at the same time in the previous year (19.4 per 100,000). Comparative model tests (Table 3) indicate the need for both trend and seasonality differencing, which AC and PAC plots indicate the need for seasonal AR and trend-level MA parameters.

The best fitting model was specified as ARIMA(1,1,0) SARIMA(0,1,1,12) (AIC=209.51) and the final modelled parameters are provided in Table 4. A plot of the observed and modelled data is provided in Figure 6. Overall the model captures both the series trend and its seasonal peaks and troughs; however there is still some period-specific variability that was not easily predicted. Overall, the observed rate of serious assault in March 2020 (18.9 per 100,000) was lower than forecast from the historical series (20.2 per 100,000), but not beyond the range of statistically plausible values for that month (18.3 - 22.1 per 100,000) (Figure 7). Still, as the observed rate is near the bottom of the confidence interval range, it will be interesting to see how the observed data for serious assault changes in April, noting that the forecast predicted a further decline, presumably as Australia enters autumn when serious assault rates normally decline.

Table 3: ARIMA Model Selection for SERIOUS ASSAULT (Feb 2014 - Feb 2020)

\begin{tabular}{|c|c|c|c|c|c|c|c|}
\hline Model & Description & Specification & Obs & 1l(model) & df & AIC & $\mathrm{BIC}$ \\
\hline 1 & Constant only & ARIMA $(0,0,0) \operatorname{SARIMA}(0,1,0,12)$ & 73 & -162.89 & 2 & 329.77 & 334.35 \\
\hline 2 & Seasonal differencing & $\operatorname{ARIMA}(0,0,0) \operatorname{SARIMA}(0,1,0,12)$ & 73 & -133.92 & 1 & 269.83 & 272.12 \\
\hline 3 & Trend differencing & $\operatorname{ARIMA}(0,1,0) \operatorname{SARIMA}(0,0,0,12)$ & 73 & -123.21 & 1 & 248.43 & 250.72 \\
\hline 4 & Seasonal \& Trend differencing & $\operatorname{ARIMA}(0,1,0) \operatorname{SARIMA}(0,1,0,12)$ & 73 & -118.66 & 1 & 239.33 & 241.62 \\
\hline 5 & Model 4 with Seasonal MA1 & $\operatorname{ARIMA}(0,1,0) \operatorname{SARIMA}(0,1,1,12)$ & 73 & -106.03 & 1 & 214.07 & 216.36 \\
\hline 6 & Model 4 with Seasonal AR1 & $\operatorname{ARIMA}(0,1,0) \operatorname{SARIMA}(1,1,0,12)$ & 73 & -113.10 & 2 & 230.19 & 234.78 \\
\hline 7 & Model 4 with Seasonal AR1 \& MA1 & $\operatorname{ARIMA}(0,1,0) \operatorname{SARIMA}(1,1,1,12)$ & 73 & -105.90 & 3 & 217.80 & 224.67 \\
\hline 8 & Model 5 with Trend MA1 & $\operatorname{ARIMA}(0,1,1) \operatorname{SARIMA}(0,1,1,12)$ & 73 & -101.75 & 3 & 209.51 & 216.38 \\
\hline 9 & Model 5 with Trend AR1 & $\operatorname{ARIMA}(1,1,0) \operatorname{SARIMA}(0,1,1,12)$ & 73 & -105.08 & 3 & 216.16 & 223.03 \\
\hline 9 & Model 5 with Trend AR1 \& MA1 & $\operatorname{ARIMA}(1,1,1) \operatorname{SARIMA}(0,1,1,12)$ & 73 & -101.65 & 4 & 211.30 & 220.47 \\
\hline
\end{tabular}

Note: Final model indicated in bold. Source: Queensland Offence rates, Open Data Portal 
A PREPRINT - MAY 2020

Table 4: ARIMA Model parameters for SERIOUS ASSAULT (Feb 2014 - Feb 2020)

\begin{tabular}{llll}
\hline \multicolumn{1}{l}{ Trend } & coeff & std. err. & $\mathrm{p}$ \\
MA1 & -0.58 & 0.12 & 0.00 \\
$\begin{array}{l}\text { Seasonal } \\
\text { AR1 }\end{array}$ & & & \\
/sigma & -0.33 & 0.12 & 0.01 \\
\hline Model: ARIMA $(0,1,1)$ SARIMA $(1,1,0,12)$ & 0.08 & 0.00 \\
\hline Sirce: & 0.96 &
\end{tabular}

Source: Queensland Offence rates, Open Data Portal

[Figure 6 about here.]

[Figure 7 about here.]

\subsection{Sexual offending}

Since February 2014, sexual offence rates in Queensland have ranged between 8.3 and 15.4 per 100,000 of the population. The observed result for March 2020 was 9.2 per 100,000. This was lower than in the previous month (11.3 per 100,000) and lower than the same time in the previous year (14.5 per 100,000). The ADF test confirmed that the series is stationary and comparative model tests (Table 5) confirm that neither trend nor seasonality differencing was required. Inspection of the AC and PAC plots indicate significant auto-correlation at lags 1 and 2 and so several specifications of the AR and MA parameters were compared.

The final and best fitting model-ARIMA(0,0,2)-required two MA parameters at lags 1 and 2 . The model parameters are presented in Table 6 and their graphical plot is provided in Figure 8. It is apparent from the fitted data that the model performs relatively poorly and does not adequately capture the high degree of volatility evidenced across the time series. There is significant fluctuation in the series which has no discernible or reliably predictable pattern. As for the observed rate of sexual offending in March 2020, the rate (9.2 per 100,000) was considerably lower than forecast by the model (11.1 per 100,000) (Figure 9). However, as was the case with both common and serious assault, this decline was within the boundary of plausible outcomes (8.3 to 13.9 per 100,000$)$ given the history of the series.

Table 5: ARIMA Model Selection for SEXUAL OFFENCES (Feb 2014 - Feb 2020)

\begin{tabular}{|c|c|c|c|c|c|c|c|}
\hline Model & Description & Specification & Obs & ll(model) & $\mathrm{df}$ & AIC & $\mathrm{BIC}$ \\
\hline 1 & Constant only & ARIMA $(0,0,0) \operatorname{SARIMA}(0,1,0,12)$ & 73 & -133.77 & 2 & 271.54 & 276.12 \\
\hline 3 & Trend differencing & $\operatorname{ARIMA}(0,1,0) \operatorname{SARIMA}(0,0,0,12)$ & 73 & -154.86 & 1 & 311.72 & 314.01 \\
\hline 5 & Model 1 with Trend AR1 & $\operatorname{ARIMA}(1,0,0)$ & 73 & -133.24 & 3 & 272.49 & 279.36 \\
\hline 6 & Model 1 with Trend MA1 & $\operatorname{ARIMA}(0,0,1)$ & 73 & -133.37 & 3 & 272.75 & 279.62 \\
\hline 7 & Model 1 with Trend AR1 \& MA1 & $\operatorname{ARIMA}(1,0,1)$ & 73 & -133.14 & 4 & 274.28 & 283.44 \\
\hline 10 & Model 1 with Trend AR2 \& MA2 & $\operatorname{ARIMA}(2,0,2)$ & 73 & -129.26 & 6 & 270.52 & 284.26 \\
\hline
\end{tabular}

Note: Final model indicated in bold. Source: Queensland Offence rates, Open Data Portal

[Figure 8 about here.]

[Figure 9 about here.]

\subsection{Breaches of Domestic Violence Orders}

The rate at which domestic violence orders are breached in Queensland has increased steadily between 2014 and 2020 . In early 2014 , the breach rate averaged at 26 per 100,000 of the population. By 2020 that had increased to a high of 62 per 100,000 . The observed DVO breach rate in March 2020 was 57.5 per 100,000 which was higher than in the previous month (55.2 per 100,000) and higher than it was in March of the previous year (52.0 per 100,000). However, we caution here on the interpretation of these rates since they are not adjusted for the number of actual domestic violence orders which are active nor the rate at which 
A PREPRINT - MAY 2020

Table 6: ARIMA Model parameters for SEXUAL OFFENCES (Feb 2014 - Feb 2020)

\begin{tabular}{llll}
\hline & coeff & std. err. & $\mathrm{p}$ \\
\hline TREND & & & \\
MA1 & 0.24 & 0.12 & 0.04 \\
MA2 & 0.36 & 0.11 & 0.00 \\
& & & \\
Constant & 10.96 & 0.16 & 0.00 \\
/sigma & 1.45 & 0.31 & 0.00 \\
\hline
\end{tabular}

Model: $\operatorname{ARIMA}(0,0,2)$

Source: Queensland Offence rates, Open Data Portal

they are issued by the courts. In the present data, the longer-term upward trend, including in the past 12 months, is likely a strong reflection of the increased number of orders being made by the courts and not necessarily any trend in the relative rate of breach events when calculated as function of the number of active orders.

Nevertheless, the ADF statistic confirmed that without adjustment the DVO breach series is non-stationary (ADF=-1.628, $\mathrm{p}=0.47$ ). Comparative model analysis (Table 7) indicated the need for both seasonal and trend differencing. AC and PAC plots suggested significant auto-correlations and partial auto-correlations at lag 1.

The best fitting model-ARIMA(1,1,0) SARIMA(0,1,1,12)-required an AR parameter at lag 1 for the trend and an MA parameter at lag 1 in the seasonal pattern (AIC=337.75). The final model specifications can be found in Table 8 the modelled results are graphically presented in Figure 10. Overall, the model fit the data with surprising precision. As for the observed breach rate of Domestic violence Orders in March 2020, the rate $(57.5$ per 100,000) was lower than forecast by the model $(59.2$ per 100,000) (Figure 11). However, again, this lower rate was within the range $(54.9$ to 63.4 per 100,000) of plausible values given the history of the series.

Table 7: ARIMA Model Selection for DOMESTIC VIOLENCE BREACH offences (Feb 2014 - Feb 2020)

\begin{tabular}{|c|c|c|c|c|c|c|c|}
\hline Model & Description & Specification & Obs & 11(model) & df & AIC & BIC \\
\hline 1 & Constant only & ARIMA( $(0,0,0)$ SARIMA $(0,1,0,12)$ & 73 & -263.96 & 2 & 531.92 & 536.50 \\
\hline 2 & Seasonal differencing & $\operatorname{ARIMA}(0,0,0) \operatorname{SARIMA}(0,1,0,12)$ & 73 & -238.26 & 1 & 478.52 & 480.81 \\
\hline 3 & Trend differencing & $\operatorname{ARIMA}(0,1,0) \operatorname{SARIMA}(0,0,0,12)$ & 73 & -197.05 & 1 & 396.09 & 398.38 \\
\hline 4 & Seasonal \& Trend differencing & $\operatorname{ARIMA}(0,1,0) \operatorname{SARIMA}(0,1,0,12)$ & 73 & -182.59 & 1 & 367.18 & 369.47 \\
\hline 5 & Model 4 with Seasonal MA1 & $\operatorname{ARIMA}(0,1,0) \operatorname{SARIMA}(0,1,1,12)$ & 73 & -172.76 & 2 & 349.53 & 354.11 \\
\hline 6 & Model 4 with Seasonal AR1 & $\operatorname{ARIMA}(0,1,0) \operatorname{SARIMA}(1,1,0,12)$ & 73 & -176.44 & 2 & 356.88 & 361.46 \\
\hline 7 & Model 4 with Seasonal AR1 \& MA1 & $\operatorname{ARIMA}(0,1,0) \operatorname{SARIMA}(1,1,1,12)$ & 73 & -172.10 & 2 & 348.19 & 352.77 \\
\hline 8 & Model 7 with Trend MA1 & $\operatorname{ARIMA}(0,1,1) \operatorname{SARIMA}(1,1,1,12)$ & 73 & -166.02 & 4 & 340.03 & 349.19 \\
\hline 9 & Model 7 with Trend AR1 & $\operatorname{ARIMA}(1,1,0) \operatorname{SARIMA}(1,1,1,12)$ & 73 & -165.11 & 3 & 336.23 & 343.10 \\
\hline 10 & Model 7 with Trend AR2 \& MA2 & $\operatorname{ARIMA}(1,1,1) \operatorname{SARIMA}(1,1,1,12)$ & 73 & -165.11 & 4 & 338.23 & 347.39 \\
\hline 11 & Model 5 with Trend AR2 & $\operatorname{ARIMA}(1,1,0) \operatorname{SARIMA}(0,1,1,12)$ & 73 & -165.87 & 3 & 337.75 & 344.62 \\
\hline
\end{tabular}

Note: Model 9 could not estimate a parameter for the Seasonal AR1 term and the term was omitted from the model.

Model 11 removes the SAR1 term and provides a superior fit to the data. Source: Queensland Offence rates, Open Data Portal

Table 8: ARIMA Model parameters for DOMESTIC VIOLENCE ORDER BREACH offences (Feb 2014 - Feb 2020)

\begin{tabular}{llll}
\hline & coeff & std. err. & $\mathrm{p}$ \\
\hline $\begin{array}{l}\text { Trend } \\
\text { AR1 }\end{array}$ & -0.42 & 0.09 & 0.00 \\
Seasonal & & & \\
MA1 & -0.80 & 0.24 & 0.00 \\
/sigma & 2.17 & 0.26 & 0.00 \\
\hline
\end{tabular}

Model: ARIMA(1,1,0) SARIMA $(0,1,1,12)$

Source: Queensland Offence rates, Open Data Portal

[Figure 10 about here.]

[Figure 11 about here.] 


\section{Discussion}

This study offers one of the first Australian-based analyses of the extent to which crime has changed during the COVID-19 pandemic. Specifically, we use an iterative univariate ARIMA framework to model the six-year trend in the state-wide rates of four violent crime types (common assault, serious assault, sexual offences and breaches of domestic violence orders) in Queensland, Australia. We capitalise on the period-by-period and seasonal patterns to generate dynamic forecasts (and their $95 \%$ confidence intervals) for comparison with the the observed rates for March 2020. We conclude that in none of the four violent crime categories was the rate of recorded crime for March significantly different from the forecast. This finding is generally consistent with other analyses conducted here in Australia and overseas.

We caution, however, in treating these early data as a definitive test of the crime-response to COVID-19. In our view, it is simply too early to make that judgement. To be sure, March 2020 was the month in which the most significant social distancing rules were first introduced in Queensland. However, their introduction occurred in the second half of the month and may not have translated (at least not yet) into a measurable change in crime rates. This is supported by Google's mobility trend data, where there was a large but gradual decrease in the use of public spaces, and an increase in time spent at home, towards the end of the March. It is possible that the impact of these containment measures, particularly in terms of influencing routine activities, will not be observable until there is a full month of data available. Similarly, the effect of major job losses and associated financial stress may also not become evident until April at the earliest. The April crime data, soon to be released in Queensland, will likely provide a more robust assessment for an entire month when social distancing was in effect. The dynamic forecasts presented in this study, and their confidence intervals, will be a useful tool in making that assessment.

Also, it is important for our readers to note that the results presented here are based on recorded crime data. We know that a significant proportion of violence crime goes unreported to police. Although the analysis of serious violence addresses this to some extent (serious violence is more likely to come to the attention of police), we cannot assume that the rate of reporting has remained stable for common assault and sexual assault. This is particularly important in the context of domestic violence, which often goes unpreported to police (Voce and Boxall, 2018). Advocates and academics have voiced concerns regarding the inability of victims to reach out for help because of isolation from family, friends and support services, fear of the abuser with whom they reside and the challenges with seeking assistance due to social distancing measures (Fitz-Gibbon and Meyer, 2020; Peterman et al., 2020; van Gelder et al., 2020). We have attempted to provide some insight into this by examining the domestic violence order breach rates, but again, we strongly warn against interpreting these data as a true measure of the extent of domestic violence. As with any procedural offence, the breach rate may be influenced by the enforcement practices of police and/or the willingness of victims to report in these unprecedented circumstances. One option worthy of further consideration in the absence of open access to data on domestic violence-related offences would be a more detailed analysis of violent offence victimisation rates by victim sex and, specifically, the long-term trend in the proportion of adult assault victims who were female. Although these data themselves suffer a number of limitations, they would provide some signal of a shift from community to home-based violence.

Related to this point, it is important to note the lack of nuance that comes from relying on aggregate crime data. It seems implausible that crimes associated with the night time economy have not been affected by the closures, since the containment measures have seen these major weekend attractions all but shut down. Violence in the night time economy accounts for a significant proportion of violence overall (Miller et al., 2016). It is plausible that the lack of an observable effect in aggregate violent crime rates is a function of competing trends between violence occurring in different contexts. For example, the decrease in violence associated with the night time economy may be offset by increases in assaults in residential settings. This can only be determined through a more detailed analysis of data on offence location, relationship between offender and victim, alcohol and drug involvement and so on.

This is an important first step in trying to understand the crime implications of the COVID-19 pandemic and associated containment measures in the Australia context. In short, it is simply too early to conclude that crime has not changed as a consequence of COVID-19, although these early figures point to stability, rather than change. Of course, the true test will come when the crime rates for April are released. When they are available, our univariate ARIMA models provide an important opportunity for a rapid and robust assessment. Ideally, these Queensland data will soon be complemented by equivalent analyses conducted with data from other Australian jurisdictions, once they are publicly available.

\section{References}

Ashby, M. (2020). Initial evidence on the relationship between the coronavirus pandemic and crime in the united states. https: //doi.org/10.31235/osf.io/ep87s

Australian Bureau of Statistics. (2019, June 27). Recorded crime - victims, australia, 2018 (Cat no. 4510.0) [Library Catalog: www.abs.gov.au Publisher: c=AU; o=Commonwealth of Australia; ou=Australian Bureau of Statistics]. Australian Bureau of Statistics. Library Catalog: www.abs.gov.au Publisher: c=AU; o=Commonwealth of Australia; ou=Australian 
Bureau of Statistics. Canberra. Retrieved April 28, 2020, from https://www.abs.gov.au/AUSSTATS/abs @ .nsf/ DetailsPage/4510.02018?OpenDocument

Australian Bureau of Statistics. (2020, April 20). Household impacts of COVID-19 survey, 1-6 apr 2020 (Cat. no. 4940.0). Australian Bureau of Statistics. Canberra. Retrieved April 27, 2020, from https://www.abs.gov.au/AUSSTATS/abs@ .nsf/Lookup/4940.0Main+Features11-6\%20Apr\%202020?OpenDocument

Australian Government Department of Health. (2020, March 28). New and cumulative COVID-19 cases in australia by notification date [Australian government department of health]. Retrieved April 26, 2020, from https://www.health.gov.au/ resources/publications/new-and-cumulative-covid-19-cases-in-australia-by-notification-date

Brooks, S. K., Webster, R. K., Smith, L. E., Woodland, L., Wessely, S., Greenberg, N., \& Rubin, G. J. (2020). The psychological impact of quarantine and how to reduce it: Rapid review of the evidence [Publisher: Elsevier]. The Lancet, 395(10227), 912-920. https://doi.org/10.1016/S0140-6736(20)30460-8

Campedelli, G. M., Aziani, A., \& Favarin, S. (2020). Exploring the effect of 2019-nCoV containment policies on crime: The case of los angeles. arXiv:2003.11021 [econ, q-fin, stat], arxiv 2003.11021. https://doi.org/10.31219/osf.io/gcpq8

Clay, J. M., \& Parker, M. O. (2020). Alcohol use and misuse during the COVID-19 pandemic: A potential public health crisis? The Lancet Public Health, O(0). https://doi.org/10.1016/S2468-2667(20)30088-8

Davey, M. (2020, April 21). Victoria police respond to family violence risk during 'very stressful time' of coronavirus [The guardian]. Retrieved April 27, 2020, from https://www.theguardian.com/australia-news/2020/apr/21/victoria-policerespond - to - family - violence - risk - during - very - stressful - time - of - coronavirus ?CMP =Share_AndroidApp_Direct_ Message

Dowling, C., \& Morgan, A. (2016). Predicting repeat domestic violence: Improving police risk assessment. Trends \& Issues in Crime and Criminal Justice, 581, 1-16.

Eisner, M., \& Nivette, A. (2020). Violence and the pandemic: Urgent questions for research. Harry Frank Guggenheim Foundation. New York.

Elbogen, E. B., \& Johnson, S. C. (2009). The intricate link between violence and mental disorder: Results from the national epidemiologic survey on alcohol and related conditions. Archives of General Psychiatry, 66(2), 152-161. https://doi. org/10.1001/archgenpsychiatry.2008.537

Europol. (2020). Catching the virus cybercrime, disinformation and the COVID-19 pandemic. European Union Agency for Law Enforcement Cooperation. The Hague, Netherlands. Retrieved April 25, 2020, from https://www.europol.europa.eu/ publications-documents/catching-virus-cybercrime-disinformation-and-covid-19-pandemic

Farrell, G., \& Tilley, N. (2020). Coronavirus: How crime changes during a lockdown [The conversation]. Retrieved April 25, 2020, from http://theconversation.com/coronavirus-how-crime-changes-during-a-lockdown-134948

Fitz-Gibbon, K., \& Meyer, S. (2020, March 18). Coronavirus: Fear of family violence spike as COVID-19 impact hits households [Lens: Pioneering research stories, commentary and opinion told by leading academics - monash university]. Retrieved April 25, 2020, from https://lens.monash.edu/@ politics-society/2020/03/18/1379841 ?slug=coronavirusfear-of-family-violence-spike-as-covid-19-impact-hits-households

Foundation for Alcohol Research and Education. (2020, April 15). Many Australians using more alcohol and worried about household drinking [FARE] [Library Catalog: fare.org.au Section: Media releases]. Retrieved April 28, 2020, from https://fare.org.au/many-australians-using-more-alcohol-and-worried-about-household-drinking/

Freeman, K. (2020). Monitoring changes in domestic violence in the wake of COVID-19 social isolation measures. Crime and Justice Statistics Bureau Brief, 145, 4.

Global Initiative Against Transnational Organized Crime. (2020). Crime and contagion: The impact of a pandemic on organized crime. Global Initiative Against Transnational Organized Crime. Geneva, Switzerland. Retrieved April 25, 2020, from https://globalinitiative.net/crime-contagion-impact-covid-crime/

Google. (2020, April 26). COVID-19 community mobility report [Google]. Retrieved April 27, 2020, from https://www.google. com/covid19/mobility

Graham, K., Bernards, S., Wilsnack, S. C., \& Gmel, G. (2010). Alcohol may not cause partner violence but it seems to make it worse: A cross national comparison of the relationship between alcohol and severity of partner violence [Publisher: SAGE PublicationsSage CA: Los Angeles, CA]. Journal of Interpersonal Violence. https://doi.org/10.1177/ 0886260510370596

Graham, K., Leonard, K. E., Room, R., Wild, T. C., Pihl, R. O., Bois, C., \& Single, E. (1998). Current directions in research on understanding and preventing intoxicated aggression [_eprint: https://onlinelibrary.wiley.com/doi/pdf/10.1046/j.13600443.1998.9356593.x]. Addiction, 93(5), 659-676. https://doi.org/10.1046/j.1360-0443.1998.9356593.x

Hulme, S., Morgan, A., \& Boxall, H. (2019). Domestic violence offenders, prior offending and reoffending in australia. Trends \& Issues in Crime and Criminal Justice, 580, 1-22.

Janda, M. (2020, April 20). COVID-19 lockdowns have cost 1.6 million australians their incomes, ABS survey shows - ABC news. Retrieved April 27, 2020, from https://www.abc.net.au/news/2020-04-20/abs- puts- early-numbers - oncoronavirus-job-losses/12164852 
Kinner, S. A., Young, J. T., Snow, K., Southalan, L., Lopez-Acuña, D., Ferreira-Borges, C., \& O’Moore, É. (2020). Prisons and custodial settings are part of a comprehensive response to COVID-19 [Publisher: Elsevier]. The Lancet Public Health, 5(4), e188-e189. https://doi.org/10.1016/S2468-2667(20)30058-X

Lum, C., Maupin, C., \& Stoltz, M. (2020, April 13). The impact of COVID-19 on law enforcement agencies (wave 1). International Association of Chiefs of Police and the Center for Evidence-Based Crime Policy, George Mason University. Washington, D.C.

Marupeng, P. (2020, April 5). Bheki cele says serious violent crimes dropped since nationwide lockdown [SowetanLIVE] [Library Catalog: www.sowetanlive.co.za]. Retrieved April 27, 2020, from https://www.sowetanlive.co.za/news/southafrica/2020-04-05-bheki-cele-says-serious-violent-crimes-dropped-since-nationwide-lockdown/

Midoes, C. (2020, April 7). Social distancing: Did individuals act before governments? Retrieved April 25, 2020, from https: //www.bruegel.org/2020/04/social-distancing-did-individuals-act-before-governments/

Miller, P., Bruno, R., Morgan, A., Mayshak, R., Cox, E., Coomber, K., Droste, N., Taylor, N., Dimitrovski, N., Peacock, A., Boxall, H., \& Voce, I. (2016). Drug and alcohol intoxication and subsequent harm in night-time entertainment districts (DASHED) (Monograph Series No. 67). National Drug Law Enforcement Research Fund. Canberra.

Mohler, G., Bertozzi, A., Carter, J., Short, M., Sledge, D., Tita, G., Uchida, C., \& Brantingham, P. (2020). Impact of social distancing during COVID-19 pandemic on crime in indianapolis.

News, A. (2020, April 9). SA police says no spike in domestic violence amid coronavirus restrictions, despite alleged murder [ABC news]. Retrieved April 27, 2020, from https://www.abc.net.au/news/2020-04-20/police-say-no-domesticviolence-spike-in-sa-during-coronavirus/12165598

Pearson, E. (2020, April 3). Family violence calls drop amid fears victims can't safely seek help while in lockdown [The age]. Retrieved April 27, 2020, from https:/www.theage.com.au/national/victoria/family-violence-calls-drop-amid-fearsvictims-can-t-safely-seek-help-while-in-lockdown-20200401-p54fzq.html

Peterman, A., Potts, A., O’Donnell, M., Thompson, K., Shah, N., Oertelt-Prigione, S., \& Van Gelder, N. (2020, April 1). Pandemics and violence against women and children (CGD Working Paper No. 528) [Library Catalog: www.cgdev.org]. Center for Global Development. Library Catalog: www.cgdev.org. Washington, DC. Retrieved April 27, 2020, from https://www.cgdev.org/publication/pandemics-and-violence-against-women-and-children

Queensland Government. (2020, April 30). Queensland offence rates - open data portal [SBS]. Retrieved April 30, 2020, from https://www.data.qld.gov.au/dataset/offence-rates-monthly-from-july-1997

Rossner, M., \& Tait, D. (2020, April 8). Courts are moving to video during coronavirus, but research shows it's hard to get a fair trial remotely [The conversation] [Library Catalog: theconversation.com]. Retrieved April 29, 2020, from http://theconversation.com/courts-are-moving-to-video-during-coronavirus-but-research-shows-its-hard-to-get-afair-trial-remotely-134386

Sarat, A. (2020, March 19). Coronavirus: Will courts continue to operate, preserving the rule of law? [The conversation] [Library Catalog: theconversation.com]. Retrieved April 29, 2020, from http://theconversation.com/coronavirus-willcourts-continue-to-operate-preserving-the-rule-of-law-134084

Semple, K., \& Ahmed, A. (2020). Murder rates were staggering. the virus has brought some quiet, for now. The New York Times. Retrieved April 27, 2020, from https://www.nytimes.com/2020/04/11/world/americas/coronavirus-murderlatin-america-crime.html

Shepherd, B. (2020, April 9). Coronavirus pressures see extra focus placed on family and domestic violence [ABC news]. Retrieved April 27, 2020, from https://www.abc.net.au/news/2020-04-09/coronavirus - family - and-domesticviolence-fears-grow/12136652

Talwar, R. (2020, April 17). Coronavirus lockdown: Domestic violence complaints in australia rise even as reports by phone fall [SBS]. Retrieved April 27, 2020, from https://www.sbs.com.au/language/english/audio/coronavirus-lockdowndomestic-violence-complaints-in-australia-rise-even-as-reports-by-phone-fall

Tate, A. (2020, April 21). Domestic violence danger during coronavirus sparks urgent calls for cash [The New Daily]. Retrieved April 27, 2020, from https://thenewdaily.com.au/news/2020/04/21/coronavirus-lockdown-domestic-violence-help/

Tuohy, W. (2020, April 12). Helpline calls by family violence perpetrators 'skyrocket' amid isolation [The age]. Retrieved April 27, 2020, from https://www. theage.com. au/national/victoria/helpline - calls - by - family - violence - perpetrators skyrocket-amid-isolation-20200410-p54iw7.html

Usher, K., Bhullar, N., Durkin, J., Gyamfi, N., \& Jackson, D. (n.d.). Family violence and COVID-19: Increased vulnerability and reduced options for support. International Journal of Mental Health Nursing, n/a. https://doi.org/10.1111/inm.12735

van Gelder, N., Peterman, A., Potts, A., O’Donnell, M., Thompson, K., Shah, N., \& Oertelt-Prigione, S. (2020). COVID19: Reducing the risk of infection might increase the risk of intimate partner violence [Publisher: Elsevier]. EClinicalMedicine, O(0). https://doi.org/10.1016/j.eclinm.2020.100348

Voce, I., \& Boxall, H. (2018). Who reports domestic violence to police? a review of the evidence. Trends \& Issues in Crime and Criminal Justice, 559, 1-16.

Weichselbaum, S., \& Li, W. (2020, March 27). As coronavirus surges, crime declines in some cities [The marshall project]. Retrieved April 25, 2020, from https://www.themarshallproject.org/2020/03/27/as - coronavirus - surges - crime declines-in-some-cities 
Women's Safety (NSW). (2020, April 2). New domestic violence survey shows impact of COVID-19 on the rise [Women's Safety (NSW)]. Retrieved April 27, 2020, from https://www.womenssafetynsw.org.au/impact/article/new-domesticviolence-survey-shows-impact-of-covid-19-on-the-rise/

World Health Organization. (2020, January 30). WHO director-general's statement on IHR emergency committee on novel coronavirus (2019-nCoV) [World health organization] [Library Catalog: www.who.int]. Retrieved April 29, 2020, from https://www.who.int/dg/speeches/detail/who-director-general-s-statement-on-ihr-emergency-committee-onnovel-coronavirus-(2019-ncov) 


\section{List of Figures}

1 New and cumulative confirmed COVID-19 cases by notification date . . . . . . . . . . . . . . 15

2 Changes in mobility over time, Australia, 15 February - 17 April . . . . . . . . . . . . . . . . 16

3 Changes in mobility (as at 31 March 2020), by location type . . . . . . . . . . . . . . . . . . . 17

4 Long-term COMMON ASSAULT rate forecasts (actual rates and ARIMA forecasts) . . . . . . . . . . . . 18

5 Short-term COMMON ASSAULT rates (actual rates and ARIMA forecasts) . . . . . . . . . . . . . . . 19

6 Long-term SERIOUS ASSAULT rate forecasts (actual rates and ARIMA forecasts) . . . . . . . . . . . . 20

7 Short-term SERIOUS ASSAULT rates (actual rates and ARIMA forecasts) . . . . . . . . . . . . . . . . 21

8 Long-term SEXUAL OFFENCE rate forecasts (actual rates and ARIMA forecasts) . . . . . . . . . . . 22

9 Short-term SEXUAL OFFENCE rate forecasts (actual rates and ARIMA forecasts) . . . . . . . . . . . . 23

10 Long-term DOMESTIC VIOLENCE ORDER BREACH rate forecasts (actual rates and ARIMA forecasts) . . 24

11 Short-term DOMESTIC VIOLENCE ORDER BREACH rate forecasts (actual rates and ARIMA forecasts) . . 25 
Figure 1: New and cumulative confirmed COVID-19 cases by notification date new cases

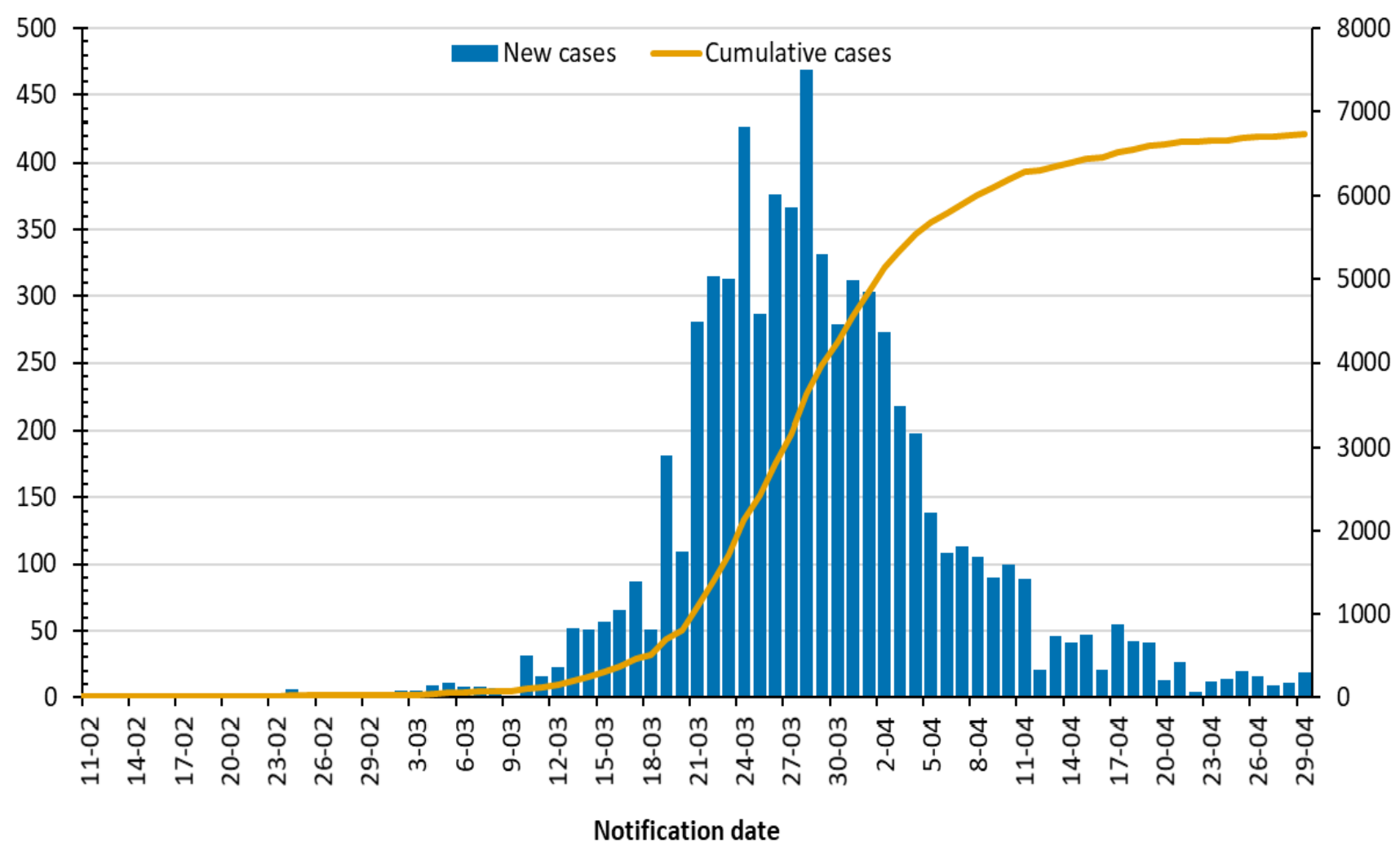

Source: Australian Government Department of Health, 2020b 
Figure 2: Changes in mobility over time, Australia, 15 February - 17 April

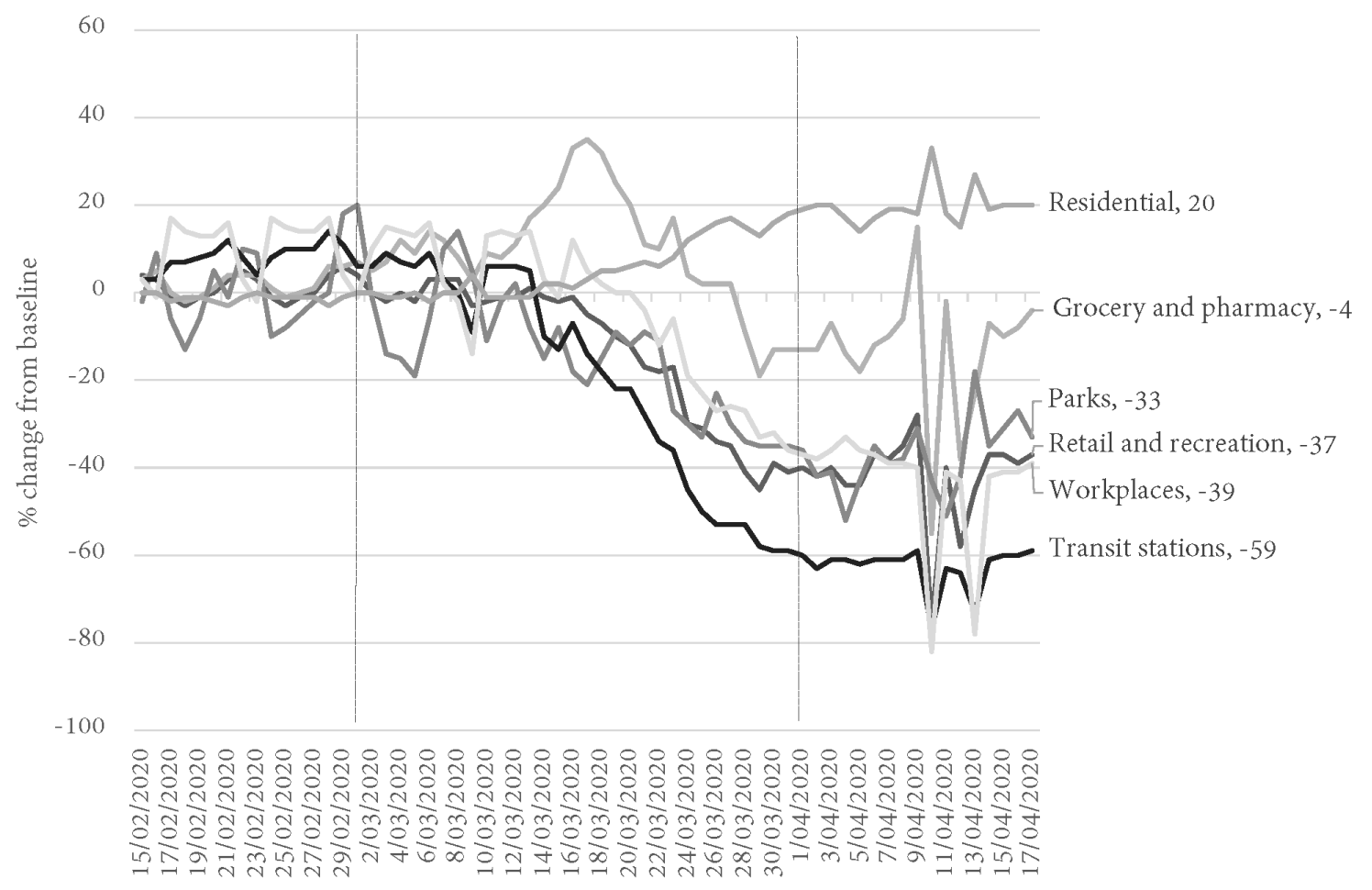

Source: Google COVID-19 Community Mobility Report 
Figure 3: Changes in mobility (as at 31 March 2020), by location type

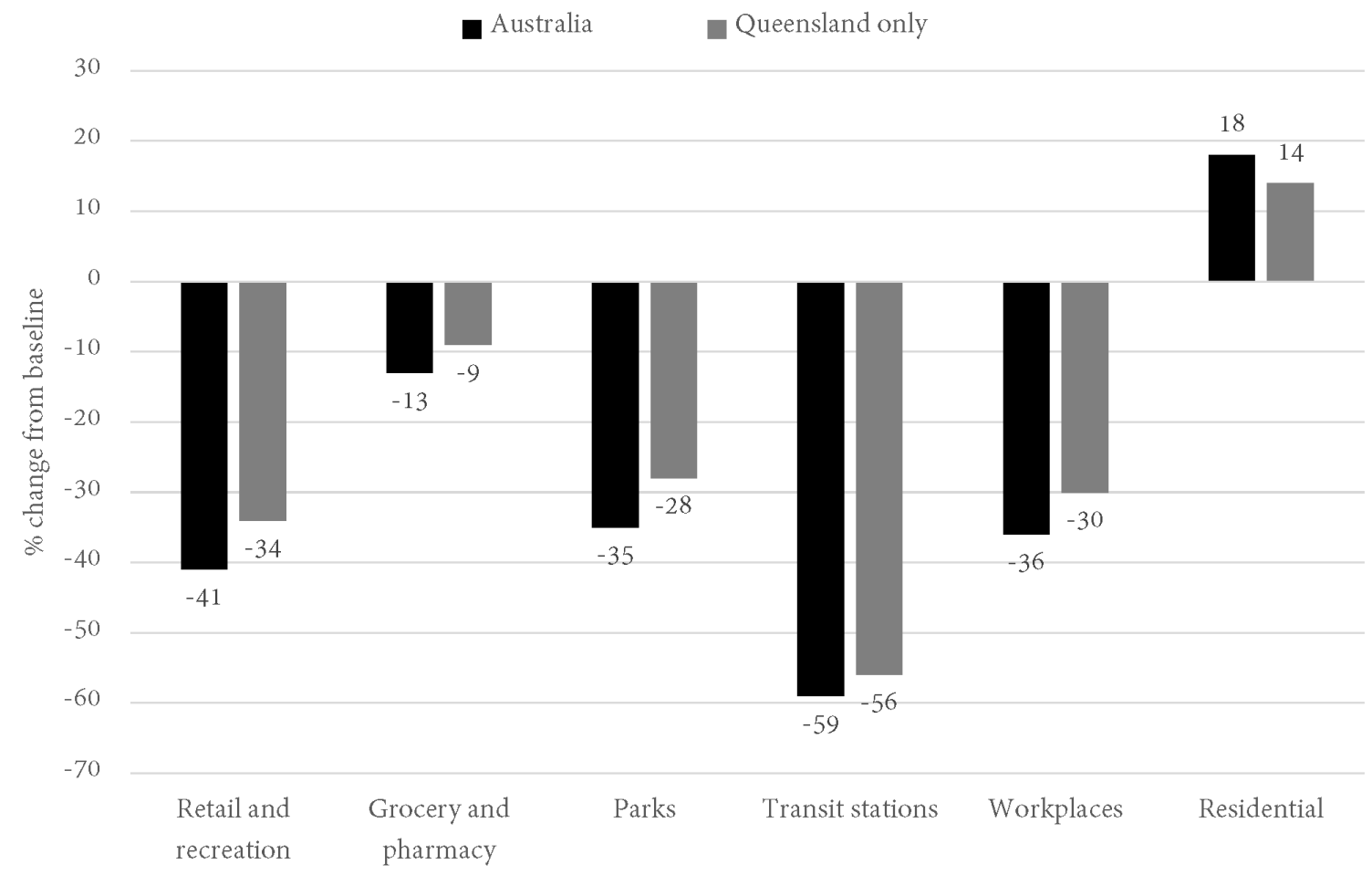

Source: Google COVID-19 Community Mobility Report 
Figure 4: Long-term COMMON ASSAULT rate forecasts (actual rates and ARIMA forecasts)

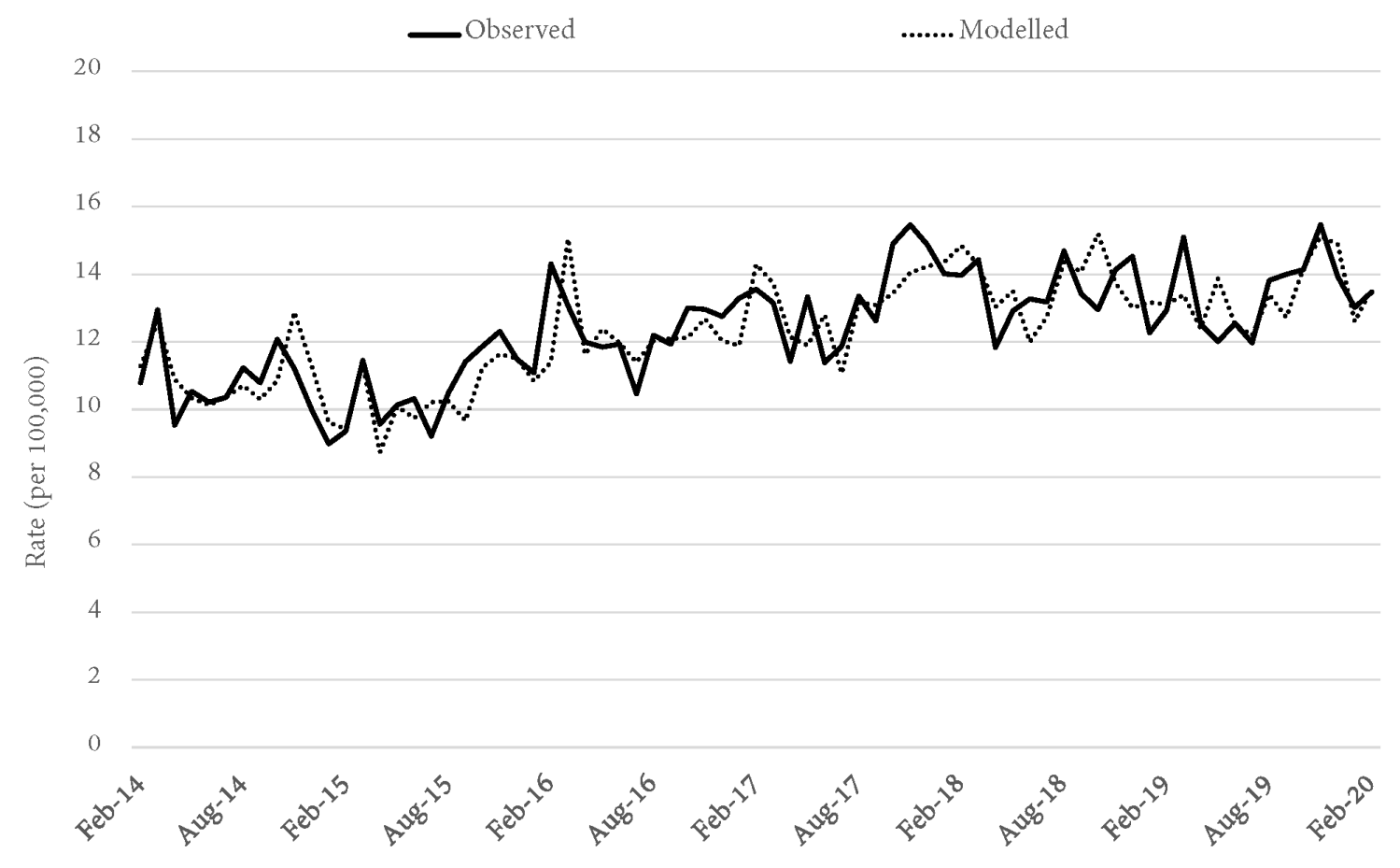

Source: Queensland offence rates, Open Data Portal 
Figure 5: Short-term COMMON ASSAULT rates (actual rates and ARIMA forecasts)

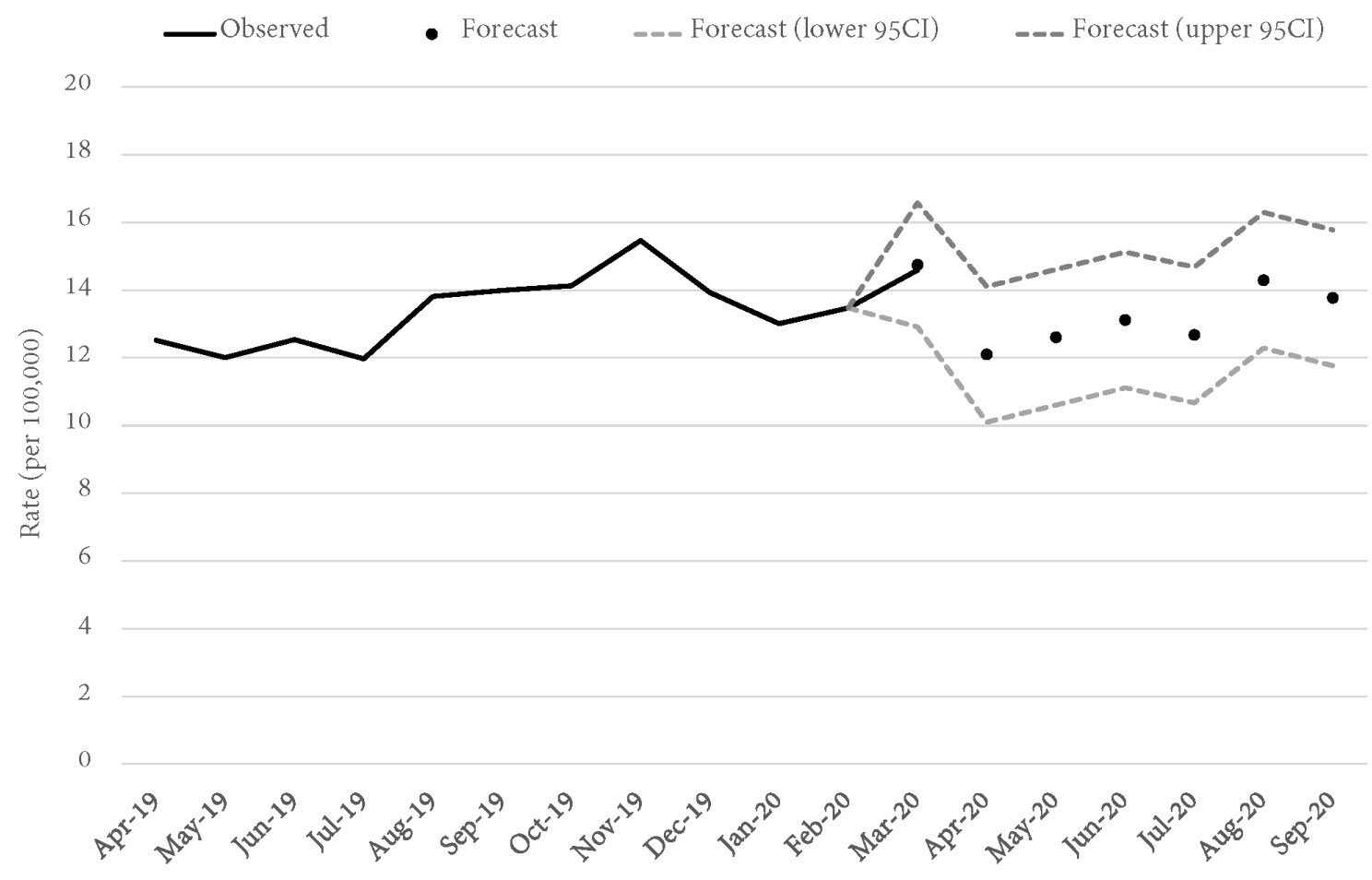

Source: Queensland offence rates, Open Data Portal 
Figure 6: Long-term SERIOUS ASSAULT rate forecasts (actual rates and ARIMA forecasts)

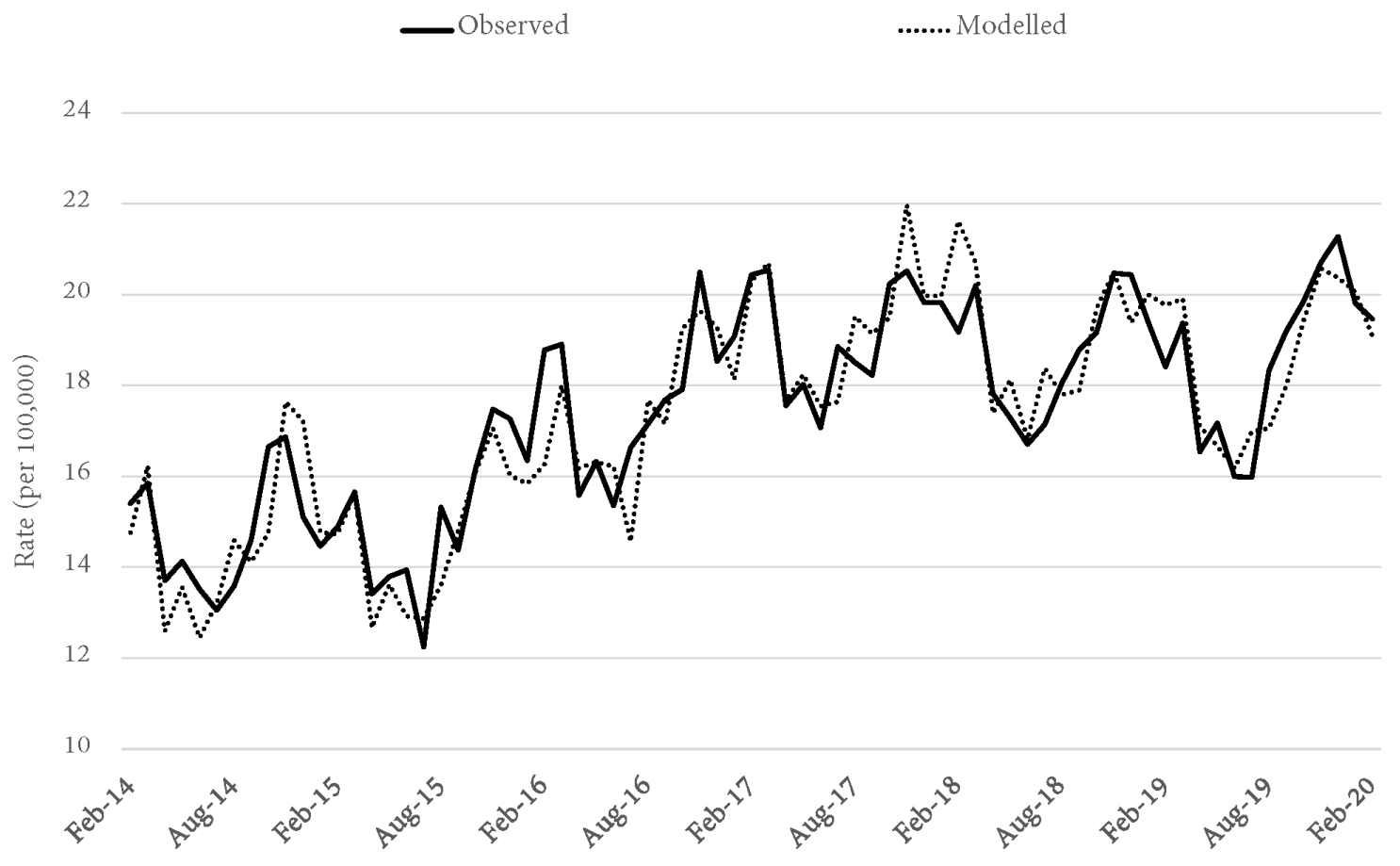

Source: Queensland offence rates, Open Data Portal 
Figure 7: Short-term SERIOUS ASSAULT rates (actual rates and ARIMA forecasts)
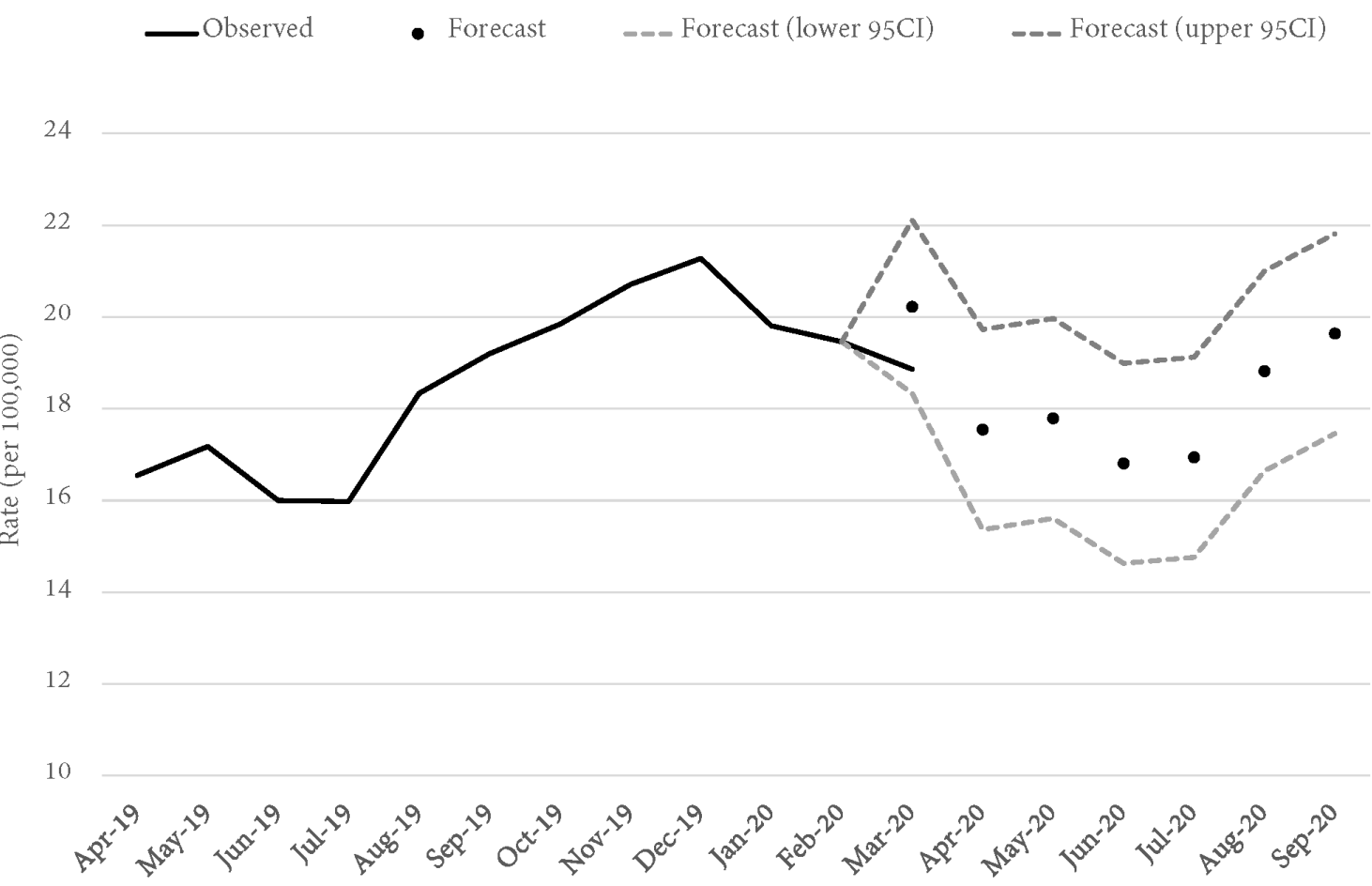

Source: Queensland offence rates, Open Data Portal 
Figure 8: Long-term SEXUAL OFFENCE rate forecasts (actual rates and ARIMA forecasts)

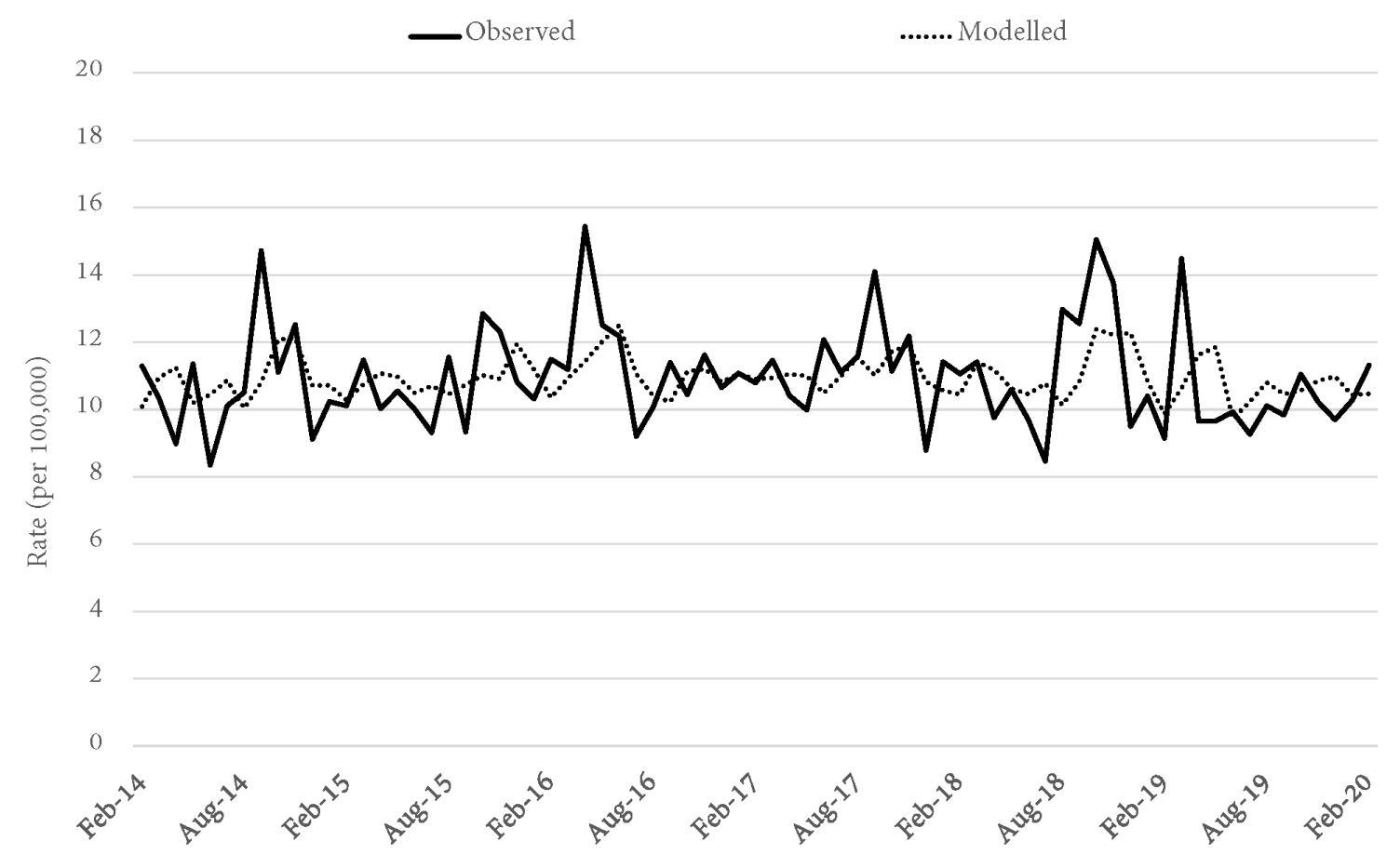

Source: Queensland offence rates, Open Data Portal 
Figure 9: Short-term SEXUAL OFFENCE rate forecasts (actual rates and ARIMA forecasts)

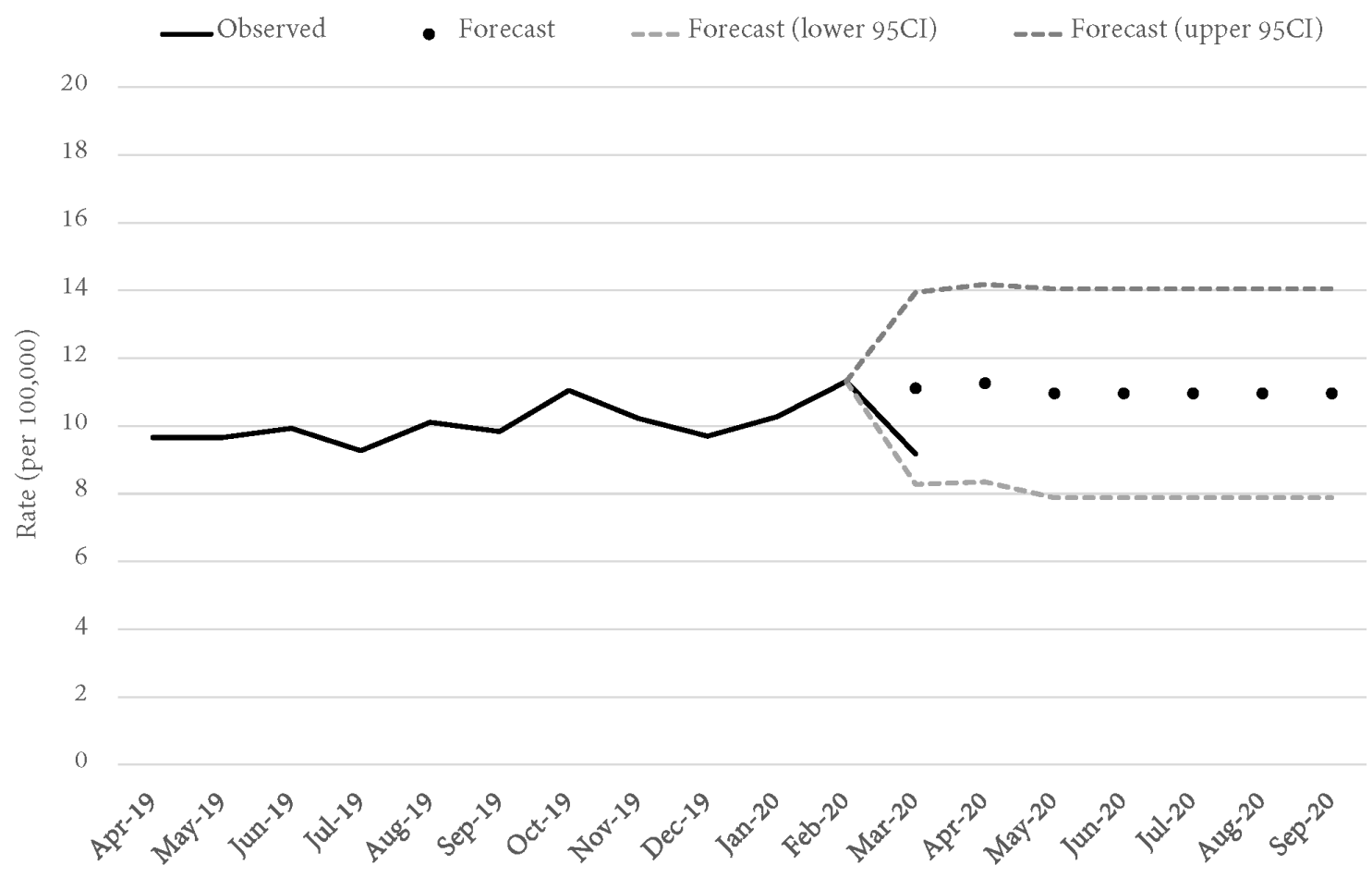

Source: Queensland offence rates, Open Data Portal 
Figure 10: Long-term DOMESTIC VIOLENCE ORDER BREACH rate forecasts (actual rates and ARIMA forecasts)

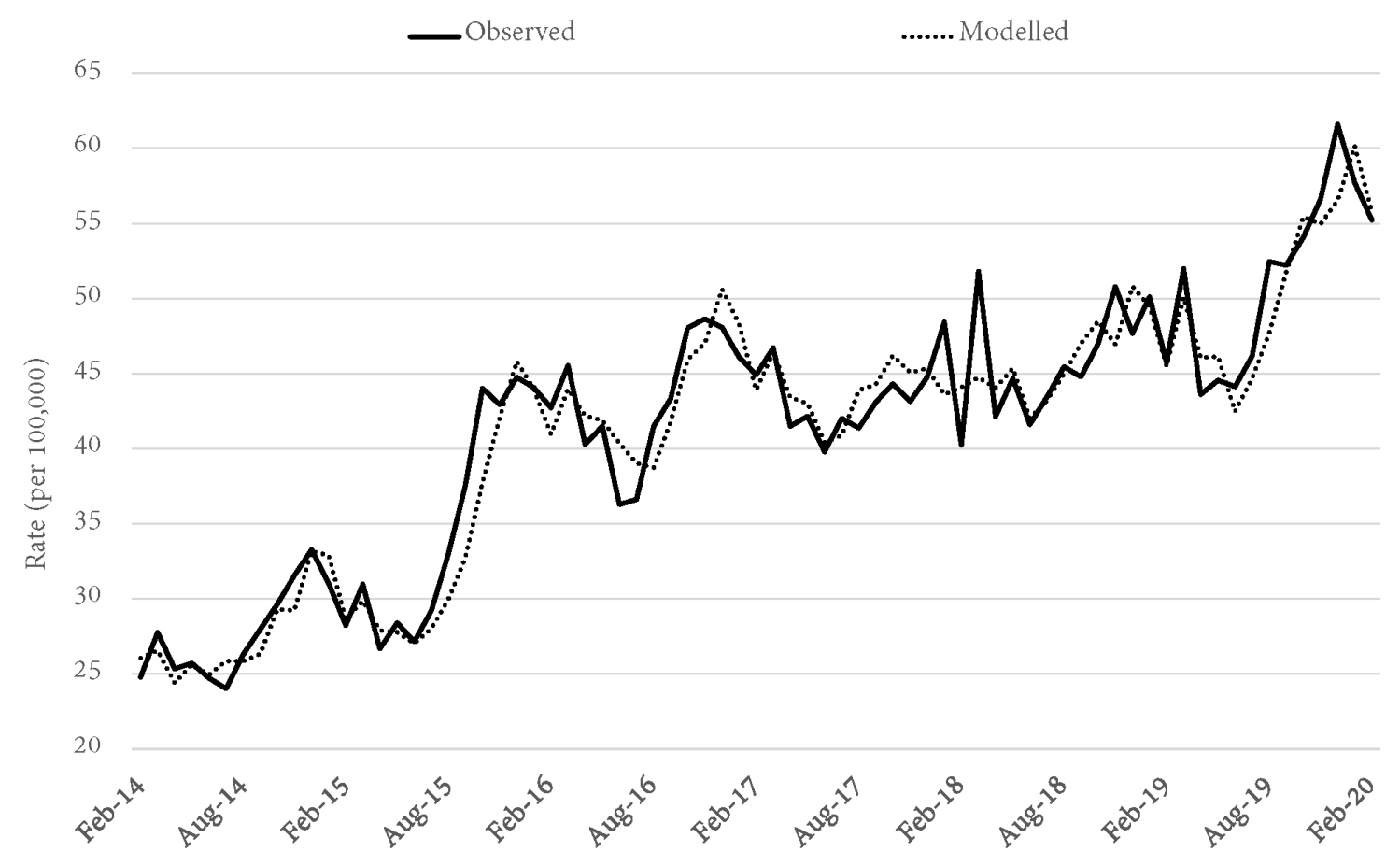

Source: Queensland offence rates, Open Data Portal 
Figure 11: Short-term DOMESTIC VIOLENCE ORDER BREACH rate forecasts (actual rates and ARIMA forecasts)

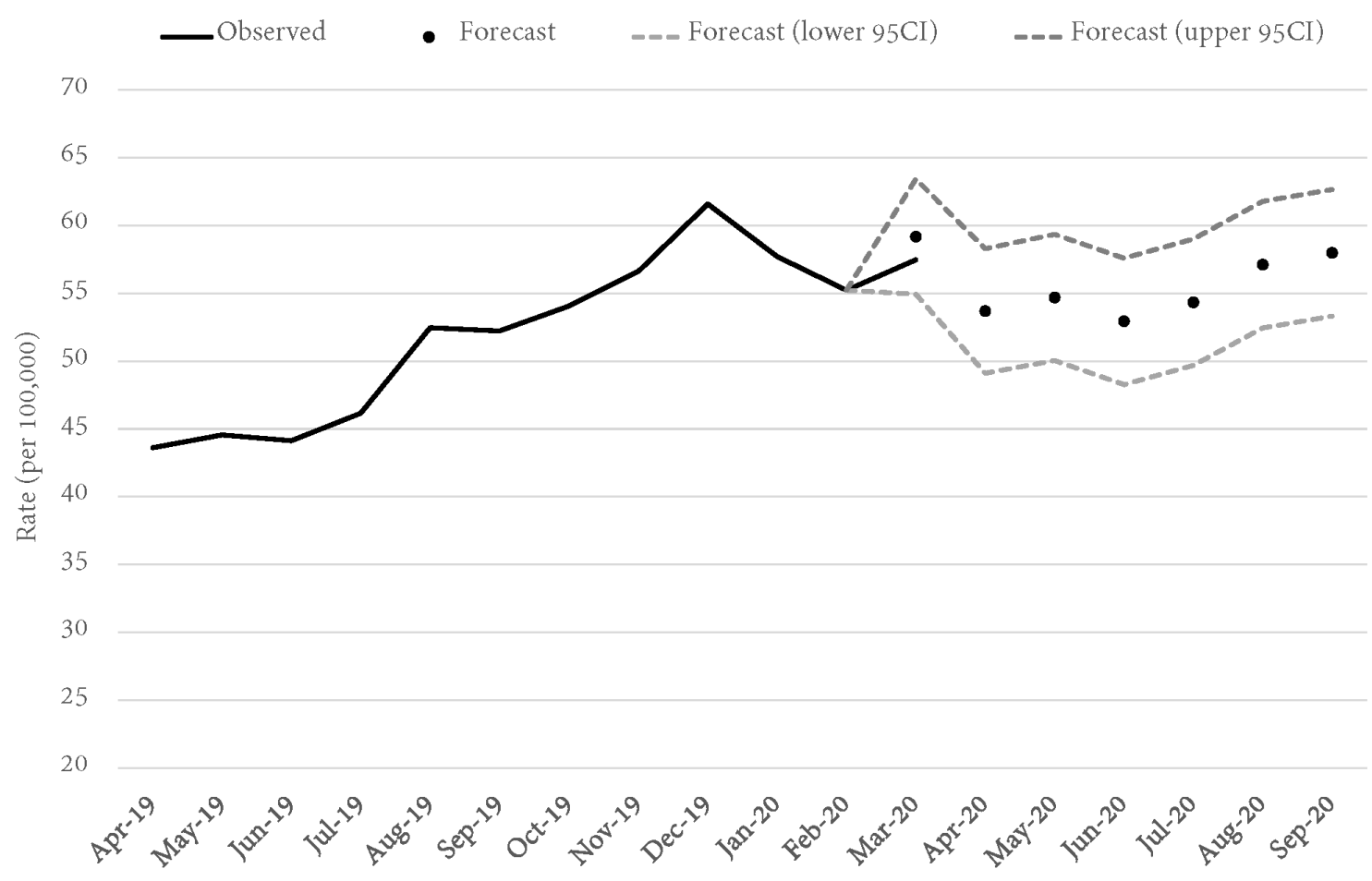

Source: Queensland offence rates, Open Data Portal 